\title{
Transdiaphragmatic plombage omentoplasty without thoracotomy for post-lobectomy bronchial fistula
}

Charles-Henri David, MD, ${ }^{\mathrm{a}}$ Xavier B. D'Journo, MD, ${ }^{\mathrm{a}}$ Hervé Dutau, MD, ${ }^{\mathrm{b}}$ and Pascal A. Thomas, MD, ${ }^{\mathrm{a}, \mathrm{c}}$ Marseille, France

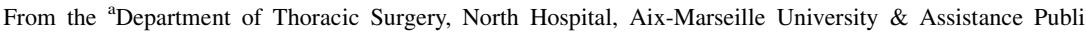
que-Hôpitaux de Marseille, Marseille, France; ${ }^{b}$ Department of Thoracic Oncology, Pleural Diseases and Interventional Pulmonology, North Hospital of Marseille, Aix-Marseille University, Marseille, France; and ${ }^{c}$ Predictive Oncology Laboratory, Centre de Recherche en Cancérologie de Marseille, Inserm UMR1068, Aix-Marseille University, Marseille, France.

Disclosures: Authors have nothing to disclose with regard to commercial support.

Received for publication Dec 28, 2018; revisions received Jan 24, 2019; accepted for publication Feb 3, 2019; available ahead of print March 8, 2019

Address for reprints: Pascal A. Thomas, MD, Department of Thoracic Surgery, North Hospital, Aix-Marseille University \& Assistance Publique-Hôpitaux de Marseille, Chemin des Bourrely, 13915 Marseille, France (E-mail: pathomas@ap-hm.fr).

J Thorac Cardiovasc Surg 2019;157:e413-5

$0022-5223 / \$ 36.00$

Copyright (C) 2019 by The American Association for Thoracic Surgery

https://doi.org/10.1016/j.jtcvs.2019.02.013
}

Video clip is available online.

Bronchial stump fistula after pulmonary lobectomy is a rare but often lethal complication. A contemporary analysis of the French national database Epithor disclosed a $0.5 \%$ prevalence, with an associated mortality of $25.9 \% .{ }^{1}$ Early recognition is crucial; however, depending on the clinical consequences of the fistula inherent in the septic and respiratory conditions of the patient, the treatment ranges from conservative strategies with chest tube drainage, through endoscopic stenting, redo bronchial suture, pleural decortication, regional muscle plombage, thoracoplasty, and eventually completion lung resection. The use of greater omental flaps is well known to be effective in the management of several complex thoracic surgical problems, ${ }^{2}$ and its specific use to repair bronchial fistulas after lower lobectomy has been reported for decades. ${ }^{3}$ We report herein a transdiaphragmatic repair of bronchial stump fistula with omentum without redo thoracotomy.

\section{CLINICAL SUMMARY}

A 60-year old, overweight man with substantial comorbidities (diabetes mellitus, stented coronary artery disease, active smoking, and synchronous early staged head and neck squamous cell carcinoma) was readmitted because of fever and abundant purulent sputum occurring 3 weeks after a robot-assisted right lower lobectomy. The first operation had been followed by an initial uneventful postoperative course, allowing discharge to home at day

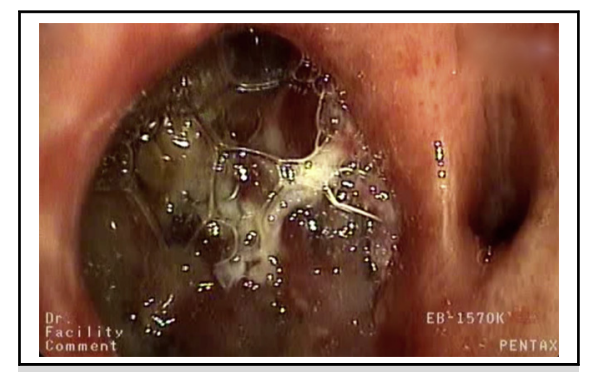

Full dehiscence of the bronchial stump.

Central Message

Transdiaphragmatic plombage omentoplasty through upper midline laparotomy without thoracotomy is a safe and efficient curative option for post-lower lobectomy bronchial fistula.

See Commentary page e417.
6. The chest computed tomographic scan (Figure 1, $A-C$ ) revealed a voluminous empty compartmentalized pleural cavity, at the top of which was a large bronchopleural fistula. Fiberbronchoscopy showed a complete dehiscence of the stapled bronchial stump (Figure 2) through which the exploration of the pleural cavity was possible, showing the absence of retained pus and few inflammatory false membranes (Video 1). Through a limited upper midline abdominal incision, a great omentum flap pedicled on the right gastroepiploic artery was harvested. The left liver lobe was then retracted gently to the right after division of the left triangular ligament to expose the hiatal area. A right posterior and sagittal phrenotomy allowed the access to the compartmentalized pleural cavity. The omental flap was then brought up transdiaphragmatically to block out the bronchial fistula and fill the cavity entirely (Figure 1, $D-F)$ and finally stitched around the diaphragmatic breach. On the basis of initial microbiologic samplings, the patient was treated with a combination of ceftazidime and metronidazole relayed by piperacillin-tazobactam for 4 weeks. Bronchoscopy performed 2 weeks after surgery showed filling of the fistula with viable omentum and tissue granulation. The postoperative course was uneventful, and the patient was discharged home on day 19. Fourteen months later, bronchoscopy showed a closed and fully epithelialized bronchial stump, and computed tomographic scan showed the absence of herniation of abdominal organs 

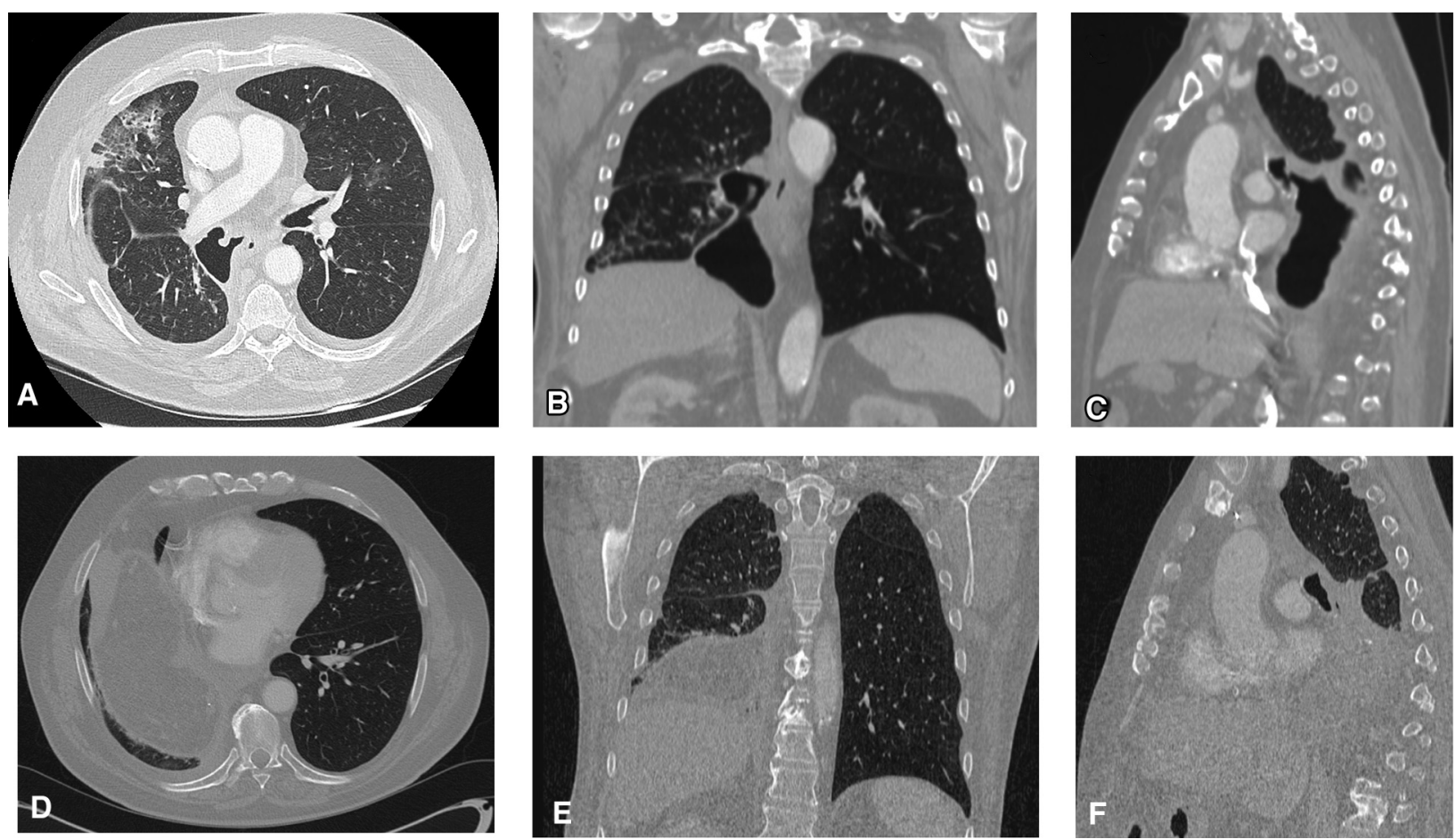

FIGURE 1. A, B, and C, Preoperative computerized tomographic scan showing a compartmentalized anfractuous pleural cavity related to a large bronchopleural fistula. D, E, and F, Postoperative computerized tomographic scan showing the complete obliteration of the pleural cavity by the great omental flap.

into the chest through the diaphragmatic defect created for passage of the omentum.

\section{DISCUSSION}

Traditional omental flap transposition requires an upper midline abdominal incision in combination with thoracotomy to mobilize the omentum before its transposition into the chest. To avoid the need for additional laparotomy, D'Andrilli and colleagues ${ }^{4}$ described a technique allowing

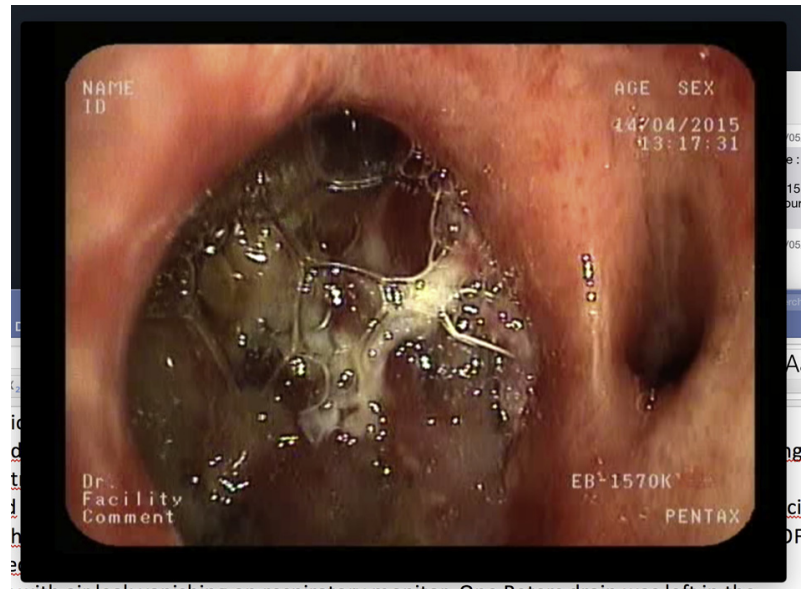

FIGURE 2. Endoscopic view of the complete dehiscence of the right lower bronchial stump. transdiaphragmatic omental harvesting through the thoracotomy. We report here the exact opposite strategy, which consisted of the harvesting then transposition of the omental flap through the diaphragm by way of the abdomen without the need for a redo thoracotomy. An alternative

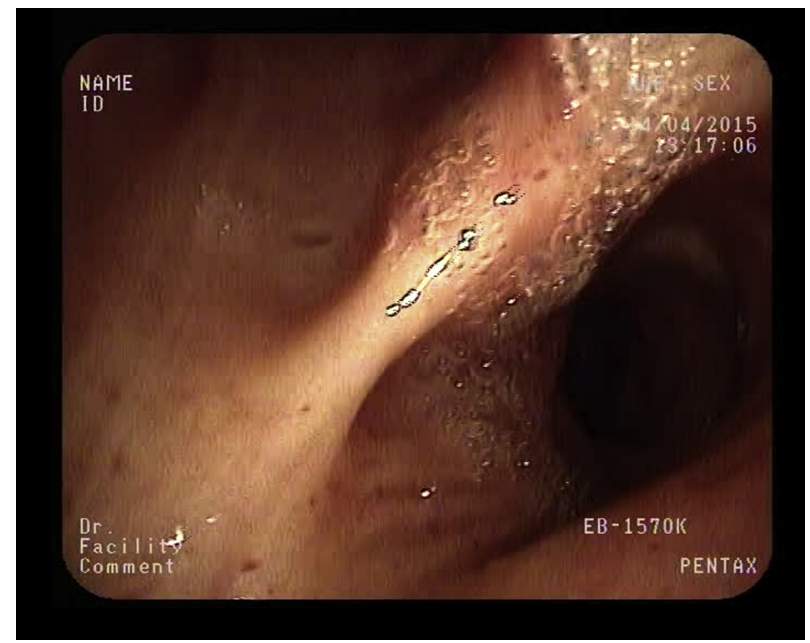

VIDEO 1. Preoperative bronchoscopy showing the complete dehiscence of the right lower bronchial stump and the exploration of the compartmentalized pleural cavity. Video available at: https://www.jtcvs.org/article/ S0022-5223(19)30445-3/fulltext. 
management strategy would have consisted of a thoracotomy with harvesting of the latissimus dorsi, which had been preserved at the time of the initial operation as a consequence of a minimally invasive approach, an attempt at direct bronchial closure, and muscle plombage of the pleural cavity. We chose the option described herein, however, to minimize the operative risk related to a redo thoracic operation and to avoid the potential functional and painful sequelae of thoracotomy, pleural decortication, and muscle transposition. We presumed that the patient's conditions (diabetes and active smoking) explained the bronchial stump failure. Local conditions were also favorable, with a clean, well-compartmentalized pleural cavity located at the dorsobasal aspect of the thorax, an organized bronchial fistula, and the absence of previous abdominal surgery. We chose the omental flap because of its excellent vascular supply and demonstrated ability to accelerate neovascularization across bronchial suture lines. ${ }^{5}$ Indeed, in the case of our overweight patient, the omentum's bulk and pliability made it particularly well suited to completely fill in an anfractuous pleural space, thereby eliminating any dead space, and to adhering closely to the bronchial stump, better than any muscle flap would have been able to do. We did not observe spreading of intrathoracic infection to the abdomen, nor were there further gastrointestinal complications.

We thus conclude that transdiaphragmatic plombage omentoplasty without thoracotomy is a safe and efficient curative option for post-lower lobectomy bronchial fistula.

\section{References}

1. Pforr A, Pagès PB, Baste JM, Thomas P, Falcoz PE, Lepimpec Barthes F, et al; Epithor Project French Society of Thoracic and Cardiovascular Surgery. A predictive score for bronchopleural fistula established using the French database Epithor. Ann Thorac Surg. 2016;101:287-93.

2. Mathisen DJ, Grillo HC, Vlahakes GJ, Daggett WM. The omentum in the management of complicated cardiothoracic problems. J Thorac Cardiovasc Surg. 1988; 95:677-84.

3. Virkkula L, Eerola S. Use of omental pedicle for treatment of bronchial fistula after lower lobectomy. Report of two cases. Scand J Thorac Cardiovasc Surg. 1975;9: 287-90.

4. D'Andrilli A, Ibrahim M, Andreetti C, Ciccone AM, Venuta F, Rendina EA. Transdiaphragmatic harvesting of the omentum through thoracotomy for bronchial stump reinforcement. Ann Thorac Surg. 2009;88:212-5.

5. Morgan E, Lima O, Goldberg M, Ferdman A, Luk S, Cooper J. Successful revascularization of totally ischemic bronchial autografts with omental pedicle flaps in dogs. J Thorac Cardiovasc Surg. 1982;84:204-10. 